\title{
The Influence of Body Size on the Ventilatory Response to Hypercapnia
}

\author{
Miharu Miyamura, Tessin Hachiya, Shūichi Hiruta, Yōji KanaO, \\ and Noriaki FujıtsuKA* \\ Laboratory for Work Physiology, Research Center of Health, \\ Physical Fitness and Sports, Nagoya University, Nagoya, 464 Japan \\ *Nagoya Institute of Technology, Nagoya, 466 Japan
}

Summary The slope of ventilatory response to hypercapnia at rest was determined in 77 healthy male students by means of the $\mathrm{CO}_{2}$.rebreathing method. It was found that the hypercapnic ventilatory response slope $(S)$ was significantly lower in the lean group with BMI (body mass index) below 19 than that in the normal group, while there were no significant correlation between $S$ and body weight or height. These results indicate that sensitivity of hypercapnia in the lean subjects differed from that of normal and overweight subjects.

Key words: hypercapnia, ventilatory response, body size.

Although there are considerable variations in the slope of ventilatory response to hypercapnia, the reasons for this scatter are not fully understood. They may be related to various factors such as age, sex, temperature, training, measurement intervals, and body size. Concerning the last factor, contradictory results have been reported by other investigators. PATRICK and HowARD (1972) reported that the slope of ventilatory response to $\mathrm{CO}_{2}$ was not significantly related to body size. By contrast, HIRSHMAN et al. (1975) found significant correlation between hypercapnic ventilatory response slope $\left(S_{i}\right)$ and height or weight, implying that some of the variation in $S$ is attributable to body size. It should be emphasized here, however, that the experiments were conducted in a small number of subjects in the case of Partick and Howard, and in forty males and four females between 21 and 51 years of age in the case of Hirshman et al., respectively.

Since females have a lower hypercapnic ventilatory drive than males (IRSIGLER, 1976; WhITE et al., 1983) and older males have significantly lower $S$ than younger men (Kronenberg and DraGe, 1973; Brischetto et al., 1984), we intended to further investigate whether the slope of ventilatory response line to

Received for publication November 7, 1984

宮村実晴，蜂矢鉄心，蛭田秀一，金尾洋治，藤墳規明 
hypercapnia is independent of body size.

Seventy-seven healthy students, age 18-26 years, participated in this study. All had not participated in any regular physical training. All subjects gave their consent after the nature of the experiments had been explained.

The subjects came to the laboratory twice. On the first day, each subject was familiarized only with the apparatus and testing procedure. The actual experiment was conducted on a separate day at least one week after from first day.

Ventilatory response to hypercapnia was determined by the rebreathing method after the subject rested in a sitting position for about $30 \mathrm{~min}$; the subject rebreathed a gas mixture (about 7\% $\mathrm{CO}_{2}$ in $\mathrm{O}_{2}$ ) of 5-6 $l$ for $4 \mathrm{~min}$ as described by READ (1967). Value for minute ventilation $(\dot{V} \mathrm{E})$ was calculated for successive $30 \mathrm{sec}$ intervals from spirometric recording. A continuous record of alveolar $P_{\mathrm{CO}_{2}}\left(P_{\mathrm{A}_{\mathrm{CO}_{2}}}\right)$ in the expired gas was obtained by drawing gas from the mouth piece through an infrared $\mathrm{CO}_{2}$ analyzer. The relationship between $P_{\mathrm{CO}_{2}}$ and $\dot{V E}$ is represented as follows: $\dot{V} \mathrm{E}=S\left(P_{\mathrm{A}_{2}}-B\right)$. The parameter $S$ of the $\mathrm{CO}_{2}$ response line is the slope representing the sensitivity to $\mathrm{CO}_{2}$ in the absence of hypoxia, and the intercept $B$ represents the $\mathrm{CO}_{2}$ threshold. $S$ was recalculated as $S_{\mathrm{N}}$ by using normalized ventilation for $70 \mathrm{~kg}$ body weight (BW), using the allometric coefficient $\mathrm{BW}^{0.75}$.

The ventilation corresponding to $P_{\mathrm{A}_{\mathrm{CO}_{2}}}$ of $60 \mathrm{mmHg}\left(\dot{V}_{\mathrm{E}_{(60)}}\right)$ was calculated from the response line to compare the magnitude of ventilation in actually measured $P_{\mathrm{AO}_{2}}$ range among the subjects, since the ventilatory response lines obtained here were located around a $P_{\mathrm{AO}_{2}}$ of about 50 to $70 \mathrm{mmHg}$ (MrYAMURA et al., 1980). Moreover, the breathing pattern was analyzed in terms of the slope and intercept ( $M$ and $K$ ) of the linear regression of ventilation to tidal volume as proposed by HEY et al. (1966): $\dot{V} \mathrm{E}=M(V \mathrm{~T}-K)$.

As described previously, PATrick and Howard (1972) have reported that there are no significant correlations between body size and the slope of ventilatory response to hypercapnia, but the number of subjects was not provided. Despite the same rebreathing method, however, HIRSHMAN et al. (1975) observed a significant correlation between $S$ and height or weight. In this study, the ventilatory response curve to hypercapnia for each subject was also measured by means of Read's rebreathing method, and the response slope is plotted against body weight and height in Fig. 1. No significant relationship between slope and body weight $(r=0.221, p>0.05)$ or height $(r=0.032, p>0.05)$ were seen. Moreover, there are no significant correlations between slope $(S)$ and body surface area $(r=0.214$, $p>0.05)$. These results basically agree with data reported by Patrick and Howard. The discrepancy of results between the present and Hirshman et al.'s studies may be due to the difference in the subjects; i.e., among their subjects are included a few women and older men.

To clarify the relation between body size and the slope of ventilatory response to hypercapnia, the body mass index (BMI, sometimes called the Quetelet index), weight in kilograms divided by the square of height in meters $\left(\mathrm{W} / \mathrm{H}^{2}\right)$, was cal- 


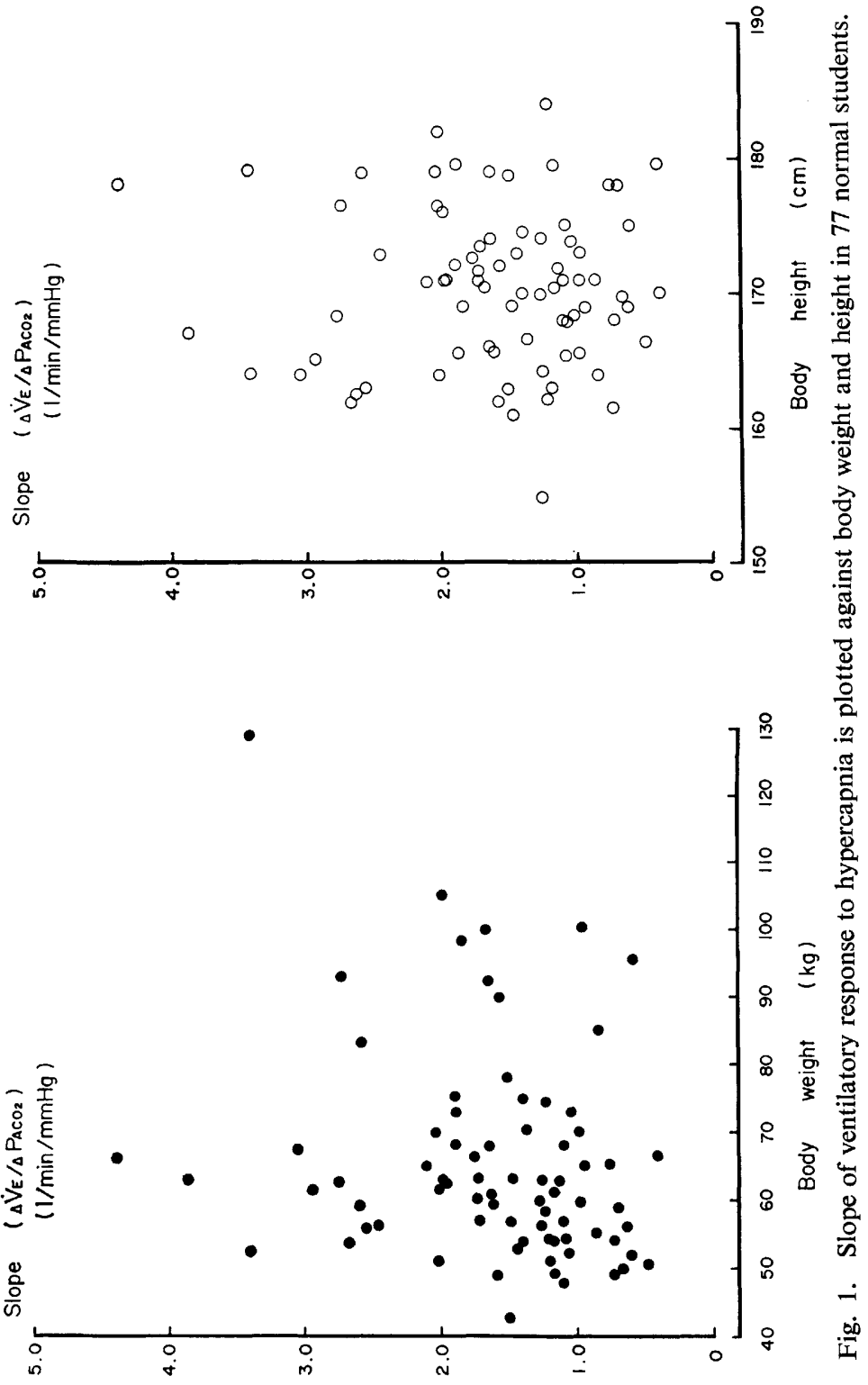

Vol. 35, No. 1, 1985 
Table 1. Physical characteristics and ventilatory response to hypercapnia in the four groups.

\begin{tabular}{lcccc}
\hline & $\begin{array}{c}\text { Group I } \\
(\text { Lean) }\end{array}$ & $\begin{array}{c}\text { Group II } \\
\text { (Normal) }\end{array}$ & $\begin{array}{c}\text { Group III } \\
(\text { Overweight) }\end{array}$ & $\begin{array}{c}\text { Group IV } \\
\text { (Obese) }\end{array}$ \\
\hline \multicolumn{1}{c}{$n$} & 19 & 43 & 5 & 10 \\
Age $(\mathrm{yr})$ & $19.5 \pm 1.1$ & $19.1 \pm 1.0$ & $19.2 \pm 1.3$ & $20.8 \pm 2.4$ \\
Weight $(\mathrm{kg})$ & $52.3 \pm 4.0^{* *}$ & $63.2 \pm 6.6$ & $73.7 \pm 5.8^{* *}$ & $98.8 \pm 12.1^{* *}$ \\
Height $(\mathrm{cm})$ & $170.6 \pm 5.0$ & $169.8 \pm 6.3$ & $172.9 \pm 6.5$ & $171.5 \pm 4.7$ \\
BSA $\left(\mathrm{m}^{2}\right)$ & $1.61 \pm 0.07$ & $1.73 \pm 0.11$ & $1.87 \pm 0.09$ & $2.11 \pm 0.16$ \\
$\mathrm{BMI}$ & $17.6 \pm 1.0^{* *}$ & $22.1 \pm 1.6$ & $26.8 \pm 0.8^{* *}$ & $33.9 \pm 2.8^{* *}$ \\
\hline$S\left(l \cdot \mathrm{min}^{-1} \cdot \mathrm{mmHg}^{-1}\right)$ & $1.15 \pm 0.50^{* *}$ & $1.79 \pm 0.86$ & $1.76 \pm 0.59$ & $1.73 \pm 0.86$ \\
$S_{\mathrm{N}}\left(l \cdot \mathrm{min}^{-1} \cdot \mathrm{mmHg}^{-1}\right)$ & $1.44 \pm 0.63^{*}$ & $1.95 \pm 0.95$ & $1.68 \pm 0.50$ & $1.31 \pm 0.57^{*}$ \\
$S / \mathrm{BSA}\left(l \cdot \mathrm{min}^{-1} \cdot \mathrm{mmHg}^{-1}\right)$ & $0.71 \pm 0.30^{* *}$ & $1.05 \pm 0.53$ & $0.93 \pm 0.27$ & $0.80 \pm 0.35$ \\
$B(\mathrm{mmHg})$ & $40.2 \pm 6.7^{*}$ & $44.3 \pm 4.8$ & $46.0 \pm 5.4$ & $42.0 \pm 10.8$ \\
$\dot{V} \mathrm{E}_{(80)}\left(l \cdot \mathrm{min}^{-1}\right)$ & $21.4 \pm 8.2$ & $26.3 \pm 12.3$ & $23.2 \pm 11.9$ & $25.1 \pm 9.8$ \\
$M\left(\mathrm{~min}^{-1}\right)$ & $23.3 \pm 7.3$ & $24.7 \pm 10.1$ & $24.7 \pm 11.9$ & $23.3 \pm 7.5$ \\
$K(l)$ & $0.22 \pm 0.32$ & $0.28 \pm 0.30$ & $0.34 \pm 0.32$ & $0.29 \pm 0.38$ \\
\hline
\end{tabular}

Values are mean \pm S.D. BSA: Body surface area, BMI: Body mass index, $S$ : Slope of ventilatory response to hypercapnia estimated from regression equation $\left(\dot{V} \mathrm{E}=S\left(P_{\mathrm{A}_{\mathrm{CO}}}\right.\right.$ $-B), S_{\mathrm{N}}$ : normalized $S$ for $70 \mathrm{~kg}$ body weight, $S / \mathrm{BSA}: S$ divided by body surface area, $B$ : intercept on the $P_{\mathrm{A}_{\mathrm{CO}_{2}}}$ axis, $M$ : Slope in Hey et al.'s equation $\left(\dot{V}_{\mathrm{E}}=M\left(V_{\mathrm{T}}-K\right), K\right.$ : intercept on the $V_{\mathrm{T}}$ axis. Significant level of difference from Group II (normal) represented by stars.

${ }^{*} p<0.05, \quad{ }^{* *} p<0.01$

culated for each subject (KeYs et al., 1972). The subjects were divided into four groups based on body mass index. Group 1: 19 lean males with BMI below 19; Group 2: 43 normal males with BMI between 20-25; Group 3: 5 overweight males with BMI 26-29; Group 4: 10 obese males with BMI over 30.

Table 1 summarizes average value and standard deviations for $S, S_{\mathrm{N}}, S / \mathrm{BSA}$, $B, \dot{V}_{(60)}, M$, and $K$ in the four groups. Average values and standard deviations of the slope $(S)$ of ventilatory response to hypercapnia were $1.15 \pm 0.50$ for the lean group, $1.79 \pm 0.86$ for the normal group, $1.76 \pm 0.59$ for the overweight group, and $1.73 \pm 0.86 \mathrm{l} / \mathrm{min} / \mathrm{mmHg}$ for the obese group, respectively. The normal, overweight, and obese groups had about the same $S$. Since hypercapnic ventilatory response is known to diminish in the subjects with obese-hypoventilation syndrome or Pickwickian syndrome, but not in those with simple obesity (Lourenco, 1969; OrensteIn et al., 1980). our obese subjects were not considered to be patients with hypoventilation syndrome.

Although significant correlation $(r=0.67, p<0.001)$ was found between parameter of Hey-plot $(M)$ and the $\mathrm{CO}_{2}$ response line $(S)$, and the lean group exhibited lower $S$ value than the normal group, average values of $M$ obtained here were almost the same in the four groups (Table 1). These results indicate that $M$ is not influenced by body size and may be a fundamental parameter of each individual's respiratory mechanism as described by HEY et al. (1966). 
On the other hand, if the slope of ventilatory response to hypercapnia at rest is related to body size, the slope obtained with a different body weight should be same when the $S$ value was recalculated after normalization of ventilation for $70 \mathrm{~kg}$ body weight $\left(S_{\mathrm{N}}\right)$ or after division by body surface area ( $\left.S / \mathrm{BSA}\right)$. However, the lean group with a BMI of lower than 19 still exhibited significantly lower $S_{\mathrm{N}}$ and $S /$ BSA values than the normal group. At present, we cannot explain the reason for lower $S$ in the lean group based on definite physiological grounds. It has been reported that catecholamine concentration increased and body temperature decreased with $\mathrm{CO}_{2}$ inhalation (BULLARD, 1964), and that raising body temperature and catecholamine cause a significant augmentation in hypercapnic ventilatory response (Cunningham et al., 1958; Natalino et al., 1977). Although lack of measurement of body temperature and catecholamine concentration in the present study made it difficult to draw valid inferences, such factors may be related to the present results. Therefore, the degree of decrement in body temperature and/ or increment in catecholamine concentration during $\mathrm{CO}_{2}$ rebreathing might differ between lean and normal subjects. However, these possibilities must be confirmed by further investigation.

\section{REFERENCES}

Brischetto, M. J., Millman, R. P., Peterson, D. D., Silage, D. A., and Pack, A. I. (1984) Effect of aging on ventilatory response to exercise and $\mathrm{CO}_{2}$. J. Appl. Physiol.: Respir. Environ. Exercise Physiol., 56: 1143-1150.

Bullard, R. W. (1964) Effects of carbon dioxide inhalation on sweating. J. Appl. Physiol., 19: $137-141$.

Cunningham, D. J. C., Hey, E. N., and Lloyd, B. B. (1958) The effect of intravenous infusion of noradrenaline on the respiratory response to carbon dioxide in man. Quart. J. Expl. Physiol., 43: 394-399.

Hey, E. N., Lloyd, B. B., Cunningham, D. J. C., Jukes, M. G. M., and Bolton, D. P. G. (1966) Effects of various respiratory stimuli on the depth and frequency of breathing in man. Respir. Physiol., 1: 193-205.

Hirshman, C. A., McCullough, R. E., and Weil, J. V. (1975) Normal values for hypoxic and hypercapnic ventilatory drives in man. J. Appl. Physiol., 38: 1095-1098.

IRSIGLER, G. B. (1976) Carbon dioxide response lines in young adults: The limits of the normal response. Am. Rev. Respirat. Dis., 114: 529-536.

Keys, A., Fidanza, F., Karvonen, M. J., Kimura, N., and Taylor, H. L. (1972) Indices of relative weight and obesity. J. Chron. Dis., 25: 329-343

Kronenberg, R. S. and Drage, C. W. (1973) Attenuation of the ventilatory and heart rate responses to hypoxia and hypercapnia with aging in normal men. J. Clin. Invest., 52: 18121819.

Lourenco, R. V. (1969) Diaphragm activity in obesity. J. Clin. Invest., 48: 1609-1614.

Miyamura, M., Fujitsuka, N., and MATsui, H. (1980) Ventilatory response to hypercapnia by rebreathing in successive trials. Jpn. J. Physiol., 30: 945-953.

Natalino, M. R., Zwillich, C. W., and WeIL, J. V. (1977) Effects of hyperthermia on hypoxic ventilatory response in normal man. J. Lab. Clin. Med., 89: 564-572.

Orenstein, D. M., Boat, T. F., Owens, R. P., Horowitz, J. G., Primiano, F. P., Germann, K., and Doershuk, C. F. (1980) The obesity hypoventilation syndrome in children with the 
Prader-Willi syndrome: A possible role for familial decreased response to carbon dioxide. J. Pediat., 79: 765-767.

PATRICK, J. M. and HowARD, A. (1972) The influence of age, sex, body size and lung size on the control and pattern of breathing during $\mathrm{CO}_{2}$ inhalation in caucasians. Respirat. Physiol., 16: 337-350.

READ, D. J. C. (1967) A clinical method for assessing the ventilatory response to carbon dioxide. Aust. Ann. Med., 16: 20-32.

White, D. P., Douglas, N. J., Pickett, C. K., Weil, J. V., and Zwillich, C. W. (1983) Sexual influence on the control of breathing. J. Appl. Physiol.: Respir. Environ. Exercise Physiol., 54: 874-879. 